and safe work for all,work-related safety actions need to include a focus on males, older workers, and workers in the primary production and transport sectors.

\section{C.002 LABORATORY SAFETY STANDARDS AND THEIR IMPORTANT IN LAB SAFETY AND TRAINING}

Neale Jackson*. Lisa J Stevens and Associates, Newport, Australia

10.1136/injuryprev-2021-safety. 197

Every year, preventable laboratory accidents either kill or maim laboratory workers. Yet despite the plethora of legislation, regulations and Standards, these incidents continue to happen. One of the key methods of reducing laboratory based incidents is AS/NZS2243 Safety in Laboratories series and AS 2982 Laboratory Design and Construction. These standards are unique as there is no other in-depth and substantive laboratory standards in the world.

This paper, using case studies, will provide an overview of AS/NZS 2243 an AS/NZS 2982 how by adopting these laboratory safety standards, that laboratory based incidents can be prevented.

\section{C.003 BARRIERS OF SAFETY PRACTICE AND HEALTH-SEEKING BEHAVIOR AMONG FISHERMEN IN COASTAL BANGLADESH}

Notan Chandra Dutta*, Aklima Anwar Mitu, AKM Fazlur Rahman, Aminur Rahman. Centre for Injury Prevention and Research Bangladesh, Mohakhali, Dhaka, Bangladesh

\subsection{6/injuryprev-2021-safety. 198}

Background Over 37 million people are involved in fishing occupation worldwide, around $90 \%$ are from Asia. Bangladesh is a riverine country bordering with the Bay of Bengal where fishing is a vulnerable occupation as they exposed to water related risks and affected by disaster. There is limited information on drowning and its health consequences among fishermen. The objectives of the study were to explore the barriers of safety practices and identifying health-seeking behavior of the fishermen in coastal Bangladesh.

Methods A qualitative study was conducted between OctoberNovember 2016 deploying IDIs, FGDs with fishermen, lenders and boat owners along with fishing practices observations. Transcribed data were coded into NVIVO-11, then analyzed by thematic contents.

Results Fishermen mentioned they prioritized livelihoods over their safety. Instability in work and financial hardship contributed to risk-taking behavior of fishermen. They usually went for fishing in sea as forced by boat-owners or local lenders from whom taking loan for fishing-net. Many women engaged in fishing with their young children and faced drowning-risks because their traditional cloths restricted free-movement in water. Fishermen usually carried first-aid box in sea, but those were not sufficient. Most of the fishermen didn't have adequate knowledge on CPR, used traditional methods in case of any drowning-case.

Conclusion Fishing occupation is high exposure to drowning risks in the coastal region of Bangladesh.

Learning Outcomes Legislation on carrying life-saving equipment on fishing boats and training on resuscitation of post drowning during fishing in sea would be crucial intervention to reduce drowning among the fishermen.

\section{C.004 LABORATORY SIGNAGE, IS THERE A CLUTTER ISSUE?}

Maria Somodevilla Torres*. The University of Queesnland, Brisbane, Australia

10.1136/injuryprev-2021-safety. 199

Work areas such as research laboratories expose workers to a variety of hazards with different risk levels. Providing adequate safety in these environments is an extremely complicated exercise that can only be achieved with adequate training as well as effective visual signage. In work places like The Australian Institute of Bioengineering and Nanotechnology, where each area is subjected to stringent government regulations on top of the inherent risks posed by the existing chemicals and instrumentation, there is a risk of over-accumulation of signage with the net result of overloading the senses of users. My Masters' literature review research project identified a number of ideal features to facilitate noticeability, visibility and comprehension of signs and it is therefore crucial to abide by best practice. Signage at my institute was collected and classified according to published and revised criteria. The analysis highlighted issues with clutter display. Effective design and placement of signage needs to be undertaken using a multidisciplinary approach incorporating social psychology, communication studies and the visual creative sciences, as well as taking into consideration cultural differences among the intended audience.

\section{C.005 POST-PREVENTION CONTROL: MODERATING THE GROUND HANDLERS' FATIGUE AND SAFETY PERFORMANCE OUTCOMES}

Muhafiza Musa*. Universiti Teknologi Petronas, Bandar Seri Iskandar, Malaysia

10.1136/injuryprev-2021-safety.200

The aircraft ground handling is widely known as complex operations with adverse working conditions in the air transport industry. The significant growth of the industry require an extensive ground handling services to cater the demand from air traveller and cargo. The ground handling workers were overwhelmed by work and prolonged fatigue, thus leading to workplace accidents or near misses. The study aims to investigate the relationship between fatigue and safety performance outcomes of ground handling workers, and to examine whether the post-prevention control of accident/incident can change the magnitude of the relationship. A sample of 523 workers were drawn from four major ground handling companies operated at Malaysia's international airports to participate the survey. The results indicated that were significant relationship between physical and emotional exhaustion with accidents and near misses as well as working condition and near misses, but not with accidents. The results also revealed that post-prevention control only influenced the physical and emotional exhaustion with near misses, in contrast with accidents or relationships between working condition with accidents and near misses. The study 